\title{
The Competition and Cooperation between China's Civil Aviation Transport and High-Speed Railway
}

\author{
Wenling Chen \\ Guangzhou Civil Aviation College, Guangzhou, Guangdong 510403 China. \\ 335312285@qq.com
}

\begin{abstract}
Competition and cooperation is a common topic in the current development of market economy, and it also occurs between China's civil air transport and high-speed railways. China's high-speed railway construction ranks first in the world. Its rapid growth and development have had a huge impact on China's air transport and will continue to affect. The paper starts with the current impact of high-speed railways on air transport, and compares various transportation impact factors such as speed, price, and transportation volume, and gives corresponding suggestions on how to reach a cooperation model for air-rail transportation. It is expected that civil air transport can in the pressure of competition, conflict with the inherent barriers to thinking, find a way to adapt to the development of the times.
\end{abstract}

Keywords: Air Transport; Civil Air Transport; High Speed Rail; Competition and Cooperation.

\section{Introduction}

Since the "11th Five-Year Plan", along with the "four trillion" investment to cope with the impact of the international financial crisis, the construction of the "four vertical and four horizontal" highspeed railway passenger transport lines nationwide has further accelerated. Several large nodes such as Beijing, Shanghai, Shenyang, Zhengzhou, Wuhan, Changsha, Chongqing, and Guangzhou are not only cities with a relatively developed social economy, but also major consumer markets for civil air transport [1]. The high-speed railway has a series of technical advantages such as fast speed, large capacity, low energy consumption and light pollution, adapting to the new demands of modern social and economic development, and developing rapidly in the world. Compared with civil aviation, highspeed trains have obvious advantages in short-distance travel, especially in the point-to-point transportation market. The competition process of high-speed railways and civil aviation includes four low-to-high levels of price competition, service competition, cost competition, and strategic competition. The comparative analysis of typical cases at home and abroad shows that the impact brought by high-speed railway is not only negative, but also has corresponding external welfare sharing. It is also a new opportunity for the restructuring of civil aviation companies, structural adjustment, and even the transformation of development methods.

\section{Comparison of Factors Influencing Civil Aviation Transport and High-speed Railway Transportation}

The paper stands on the customer's point of view and consists of five categories: currency price, time value, transport capacity, objective security, and on-time efficiency. The five types of selection factors also reflect the technical and economic characteristics of the two modes of transportation, and this difference not only affects the formulation of macro-policies, but also the micro-competition [2]. 


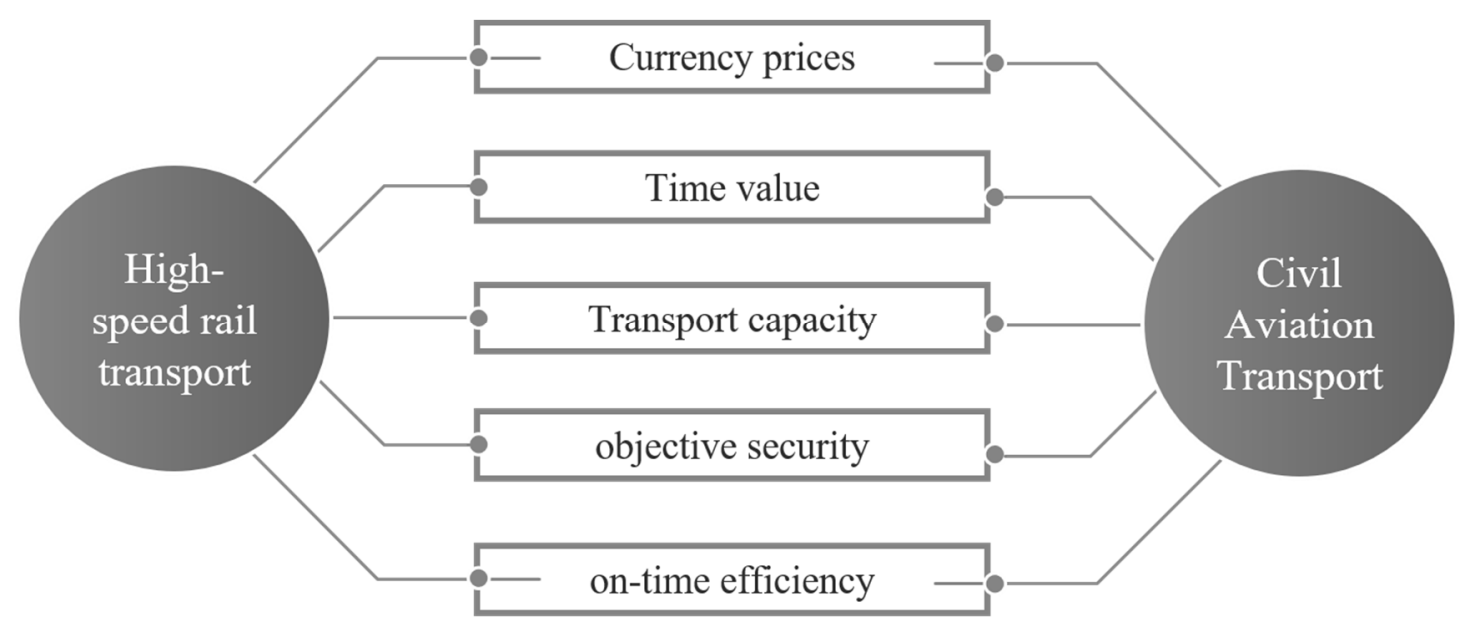

Fig 1. Comparison of Influencing Factors of Civil Aviation Transport and High-speed Railway Transportation

\subsection{Currency Price}

The high-speed rail passenger line has higher technical standards, higher construction costs and operating costs, resulting in high-speed rail fares, and some even exceed the price of civil aviation. But at the same time, because high-speed rail can bring huge benefits to the society and greatly promote the national economy, the construction and operation of high-speed rail can be strongly supported by the state and reduce its transportation costs [3]. Therefore, the high-speed rail still has a certain low price. Advantage. In addition, the high-speed trains are also more convenient for retiring and signing, and high-speed rail has a great advantage over the high cost of civil airline ticket reimbursement. The full-price ticket for civil aviation is higher than the high-speed rail fare, plus the built-in fuel costs, taxes, etc., even after the seasonal fare discount is still not low.

\subsection{Time Value}

Passengers have a convenient need for transportation. No matter which type of transportation is used, its convenience is an important factor affecting its competitiveness. In the range of 200 to 1000 $\mathrm{km}$, the total travel time of high-speed railways is comparable to that of aviation. The high-speed railway has improved the convenience by speeding up and narrowed the speed gap with aviation, which has created a huge competitive pressure on civil aviation [4].

\subsection{Transport Capacity}

The high-speed rail has large capacity and flexible capacity. Take the Beijing-Shanghai high-speed railway put into operation as an example. According to the initial operational capacity plan announced by the Ministry of Railways, 90 pairs of trains are operated every day, with 1,000 long columns for each row, and Beijing-Shanghai (one-way) can provide more than 40,000 per day. Seats; while airlines on the Beijing-Shanghai route on one-way supply of seats from 1.2 to 15,000 , high-speed rail transport capacity is 2 to 3 times the air transport capacity. The EMU has a flexible layout. On the one hand, the number of seats per train can be adjusted by length and length. On the other hand, the number of pairs of trains that can be operated on a daily basis can be adjusted to meet the changes in market demand. It is impossible to frequently adjust (increase/decrease) regular flights on a large scale, and the market adaptability is obviously inferior to that of high-speed railways.

\subsection{Objective Security}

The operation of the high-speed rail realizes the automation operation of the fully enclosed environment and has a series of perfect security guarantee systems. The civil aviation operation is a strict security check that performs normalization, both of which have high security performance. 


\subsection{On-time Efficiency}

High-speed rail is generally not affected by the climate, plus fully enclosed automatic operation technology, with strong regularity and high punctuality rate; civil aviation is affected by weather, air traffic, technical services and other conditions, which is likely to cause flight delays and delays, reliability Lower, but the recovery efficiency is superior to high-speed rail, such as the impact of extreme conditions such as floods and mudslides.

Tab 1. Comparison of main selection factors for high-speed railway and civil aviation

\begin{tabular}{|c|c|c|}
\hline \multirow{2}{*}{$\begin{array}{l}\text { Selection } \\
\text { factor }\end{array}$} & \multicolumn{2}{|c|}{ Transportation method } \\
\hline & High Speed Rail & Civil Aviation \\
\hline $\begin{array}{l}\text { Currency } \\
\text { prices }\end{array}$ & $\begin{array}{l}\text { The overall price level is low, } \\
\text { The short-term cost advantage is obvious. }\end{array}$ & $\begin{array}{c}\text { The overall price level is high, } \\
\text { Long-distance cost advantages are } \\
\text { obvious. }\end{array}$ \\
\hline $\begin{array}{l}\text { Time } \\
\text { value }\end{array}$ & $\begin{array}{c}\text { Slower but less redundant } \\
\text { There are obvious advantages within } 1000 \\
\text { kilometers. }\end{array}$ & $\begin{array}{c}\text { Faster but more redundant } \\
\text { There are obvious advantages over } 1000 \\
\text { kilometers. }\end{array}$ \\
\hline $\begin{array}{l}\text { Transport } \\
\text { capacity }\end{array}$ & \multicolumn{2}{|c|}{$\begin{array}{l}\text { Quality of service, security checks, waiting for the environment, going to the process, } \\
\text { baggage restrictions, decent and comfort, psychological experience, etc. }\end{array}$} \\
\hline $\begin{array}{l}\text { objective } \\
\text { security }\end{array}$ & $\begin{array}{l}\text { Safe operation will be time tested } \\
\text { The psychological basis of security is more } \\
\text { solid. }\end{array}$ & $\begin{array}{l}\text { More mature security mode, } \\
\text { The probability of safety is higher in terms } \\
\text { of probability. }\end{array}$ \\
\hline $\begin{array}{l}\text { on-time } \\
\text { efficiency }\end{array}$ & $\begin{array}{l}\text { Very few late operations except for very } \\
\text { special weather conditions }\end{array}$ & $\begin{array}{l}\text { It is easily affected by weather, services, } \\
\text { technology, and control. }\end{array}$ \\
\hline
\end{tabular}

\section{Analysis of Competition and Cooperation between Civil Aviation Transport and High-Speed Rail}

\subsection{Competition Analysis}

The various competitions between high-speed rail and civil aviation in the passenger transport market are reflected in the products and services as well as the unique technical and economic characteristics of the transport industry, such as departure and arrival times, comfort, and security. Relatively speaking, when civil aviation has the characteristics of high speed and high quality, it will attract a large number of business travelers. High-speed rail has the advantages of convenience, comfort and low fares, and will be favored by many fare-sensitive travelers. Next, passengers choose their own mode of transportation according to their preferences for transport services of different qualities provided by transport companies. Transport companies compete for customer sources by improving the technical and economic characteristics of transport products, and the performance of high-speed rail and civil aviation can be further improved. Stimulate passenger demand growth.

Demand for passenger transport is the main source of income for transport companies, and it is the main objective of competition between high-speed rail and civil aviation. Passenger transport demand can be expressed as follows by means of general functional formulas.

$$
Q=Q\left(P, Y_{1}, \ldots \ldots Y_{j} \ldots Y_{m}\right)
$$

Among them, Q represents the passenger transportation demand; P represents the transportation price; $Y_{j}$ includes all the influencing factors except the price, including income, GDP and so on. 


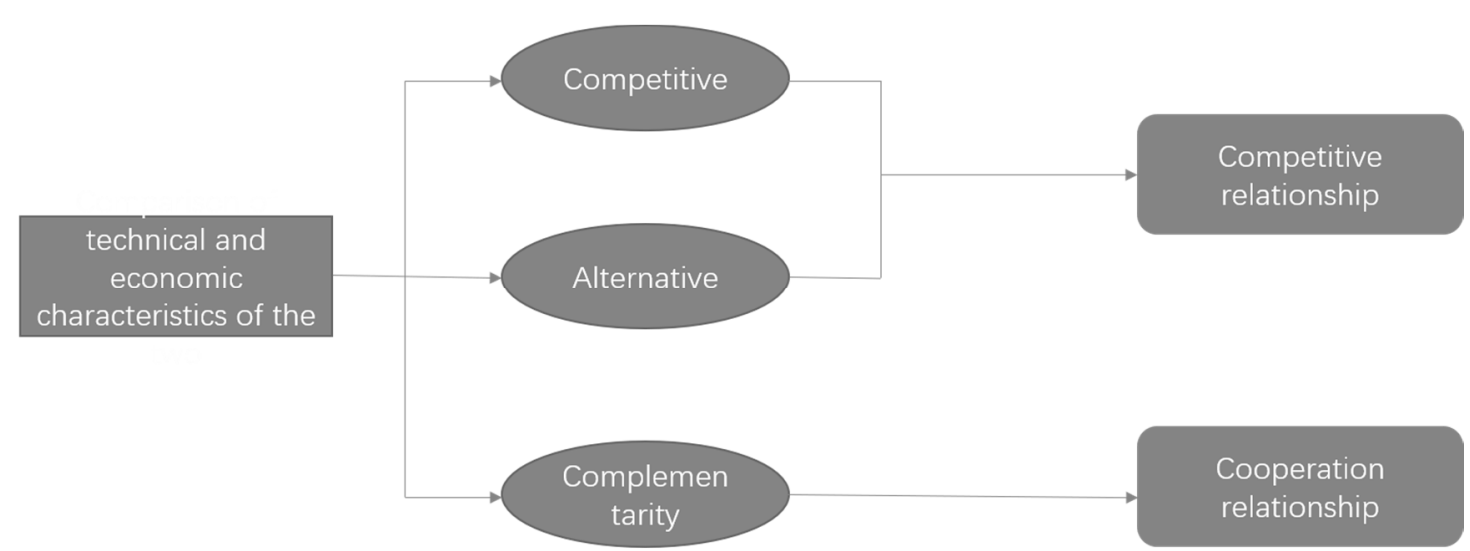

Fig 2. Relationship between the two determined by the technical and economic characteristics

\subsection{Cooperative Analysis}

The advantages and disadvantages of the technical and economic characteristics between the highspeed railway and the civil aviation transportation have determined that both have their own advantages. However, the travel demand of human beings is not strictly matched with the advantages of a certain type of transportation. There is a certain difference between the two. With the rapid development of the economy and society, people are increasingly demanding travel. This mismatch is getting worse. This has led to the emergence of "combination supply", that is, for a travel demand, through the cooperation between two or more modes of transportation! [40]: Its emergence can be said to be in the history of transportation. A great change. It makes the technical and economic characteristics of transportation supply no longer single. It is determined by the technical and economic characteristics of a certain transportation mode, but by the technical and economic characteristics of various transportation modes involved in completing the entire displacement process. The decision has effectively compensated for the inadequacies of the supply characteristics of a single mode of transportation and can fully utilize the advantages of various modes of transportation and transportation to better meet people's ever-changing travel needs.

For example, after the French high-speed railway company TGV successively opened Paris to Lyon, Paris to Marseille, Air France gradually withdrew from these markets. Travelers spend two hours on the market, TGV accounted for $90 \%$ to $95 \%$ of the market; 3 -hour market, TGV It accounts for $60 \%$ of the market share. In the passenger market of 4 hours and above, TGV has a 38\% share. In the face of the competitive landscape brought by high-speed rail and high-speed rail transport, the European civil aviation industry has taken prompt measures to respond positively. In 1998, Lufthansa Airlines took a crucial step towards win-win cooperation between airlines and railways. In August 2008, Air France also announced that it has teamed up with Veolia Transportation, the world's largest private bus operator, to launch high-speed rail passenger services after the opening of the international railway passenger transport market on January 1, 2010. Air France's launch of high-speed rail international passenger services is a strategic adjustment. Due to operating costs, Air France's operations on routes that cost less than three hours from London to Paris and from Amsterdam to Paris have been unsustainable, turning the confrontation into cooperation.

\section{How to Cooperate}

As civil aviation transportation, it is necessary to work hard to promote the consensus of the industry to cope with the challenge of the high-speed rail; actively promote the overall response of the industry to the introduction of policies, actively promote the introduction of relevant policies that benefit the air transport industry; promote overall planning of transportation, give full play to transportation advantages, strengthen cooperation and various Seamless communication in the form of traffic. Actively integrate into the national transportation planning, give full play to its advantages, and strengthen cooperation with high-speed rail in hub construction, code sharing, network transit, 
passenger transportation, marketing cooperation, channel and customer sharing, and point exchange, and actively capture the opportunities brought by high-speed rail.

For example, "Beijing-Shanghai Pass", the fare of the Beijing-Shanghai high-speed railway will be significantly higher than the average fare level of the railway, and the composition of the passengers attracted will be much higher than the average consumption level of the railway passengers. Therefore, for airlines, this part of the target population is extremely market potential. For high-speed rail, building a brand to establish a higher service standard process and achieving greater benefits is a problem to be solved. Therefore, airlines can make full use of their own route network and transit capacity to meet the transit needs of these passengers through cooperation with high-speed railways. In addition, airlines can also cooperate with high-speed rail departments in a deeper level, similar to aviation. Code sharing between companies, and the implementation of highspeed rail brand implementation, help the high-speed rail upgrade service standards, opened the "land business class", the two sides can implement revenue sharing, thereby increasing the high-speed rail brand influence while also expanding the airline's passenger source, the high-speed rail passenger flow is closely integrated with the airline's airline network, and a new "Blue Ocean Value Area" is created.

For example, the "After entering Beijing in Tianjin" air-rail intermodal product is the beginning of a cooperation between China's high-speed rail department and airlines: it was jointly launched by Tianjin Airlines, Tianjin Airport and Beijing-Tianjin Inter-city Co., Ltd. If passengers choose to take the Tianjin Airlines flight to Tianjin first, they will get free airport bus tickets to Tianjin East Station and Beijing-Tianjin intercity ticket. Through the seamless connection between the airport bus and the EMU, the total travel time from the Tianjin Airport to Beijing South Railway Station is about one hour. It is only half an hour from the Capital Airport to Dongzhimen, but the ticket price is much cheaper. Taking Hangzhou to Beijing as an example, the current ticket price level is about 1080 yuan, and Hangzhou Fei Tianjin only needs 700 yuan. Therefore, "Jingjin Beijing" still has a great attraction. The passenger flow of the Capital Airport is becoming increasingly saturated, and airspace resources are scarce. The "Jingjin Beijing" products divert passenger flow from the Capital Airport and will also enhance the radiation range and competitiveness of Tianjin Airport.

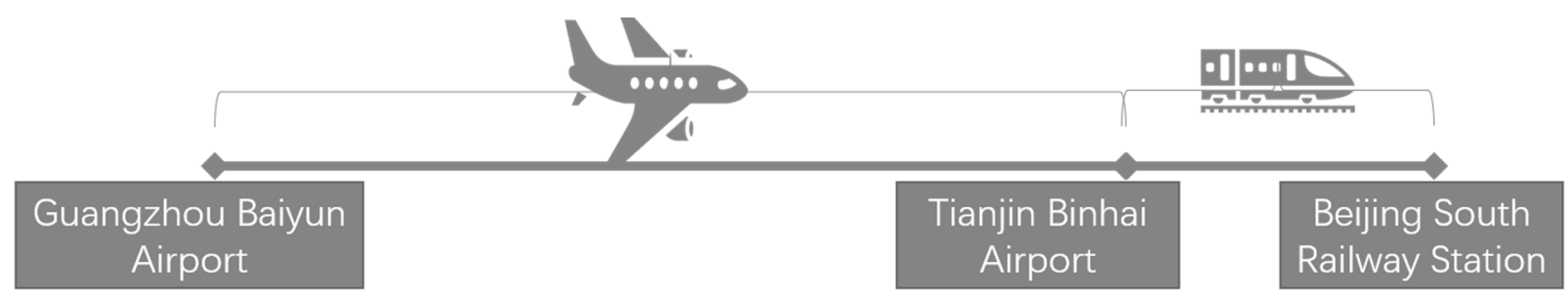

Fig 3. Transportation options from Guangzhou to Beijing

\section{Conclusion}

In short, when competition is inevitable, in addition to actively responding to the challenges posed by rivals, in-depth research and discovery of complementary cooperation with competitors will help each other to learn from each other and turn disadvantages into positive factors. To make the market bigger is a feasible way.

\section{References}

[1]. Ding Jinxue, Jin Fengjun, Wang Wei, et al. Competitive game between high-speed rail and civil aviation and their spatial effects: Take Beijing-Shanghai high-speed rail as an example. Economic Geography, Vol. 5 (2013) No. 33, p. 104-110.

[2]. He Wei. Research on the competition relationship between high-speed railway and civil aviation in China. Beijing Jiao tong University, Vol. 3 (2013) No. 37, p. 125-128. 
[3]. Yan Peidi, Han Hong. Analysis on the Characteristics of Competition Factors in China High Speed Railway Passenger Transport Market. Railway Economics Research, Vol. 4(2016) No. 25, p. 35-38.

[4]. Xie Yingyi. Research on competition between high-speed railway and civil aviation market. Beijing Jiao tong University, Vol. 2(2017) No.25, p. 125-128.

[5]. Li Wei. Synergetic Development of High-speed Railway and Civil Aviation under the Comprehensive Traffic Environment. Railway Economics Research, Vol. 9(2018) No. 37, p. $125-132$. 